\title{
The Effect of Chemical Elements on the Machinability of Aluminium Alloys
}

Jan Madl, Ludek Ruzicka, Michal Lattner

J. E. Purkyne University in Usti nad Labem, Faculty of Production Technology and Management. Pasteurova 3334/7, 40001 Usti nad Labem. E.mail: madl@fvtm.ujep.cz

Machinability of materials is evaluated by different criteria. The basic evaluative criteria are based on tool wear. However, there are other criteria, for instance chip formation, cutting temperature, forces of cutting, etc. Machinability for different criteria depends on many factors, of which the most important is the chemical composition of the material. It is possible to divide machinability tests into two groups: Long-term tests and short-term tests. Short-term machinability tests are less objective than long-term ones, but they have the advantage of short duration and lower material consumption. This paper is focused on the experimental determination of the effect of chemical composition on the machinability of aluminium alloys. For testing three different short-term tests were used. The results were evaluated by correlation coefficients. All used tests led to the same results.

Keywords: machinability, aluminum alloys, chemical elements, machinability tests

\section{References}

[1] MÁDL, J. Experimentální metody v obrábění. ČVUT: Praha, 1988.

[2] KOCMAN, K., PROKOP, J. Technologie obrábění. 2. vyd. Brno: Akademické nakladatelství CERM, 2005. 270 s. ISBN 80-214-2068-0.

[3] BAMBULA, M. Hodnocení obrobitelnosti slitin hliníku - kritéria hodnocení Brno: VUT, FS, ÚST. 2008. 27 s.

[4] HUMÁR, A. Technologie I, Technologie obrábění - 1. část [online] VUT v Brně, FS, 2003. 138 s. Avaible on WWW: 〈http://ust.fme.vutbr.cz/obrabeni/opory-save/TI_TO-1cast.pdf>.

[5] MÁDL, J., SCHUBERT, V. Experimentální metody a optimalizace v teorii obrábění. Praha: ČVUT, 1985.

[6] MICHNA, Š., LUKÁČ I., OČENÁŠEK V. et al. Aluminium materials and technologies from A to Z. Přerov: Adin, s. r. o., 2007. 632 s. ISBN 978-80-89244-18-8.

[7] MICHNA, Š. et al. Encyklopedie hliníku. 1. vyd. Prešov: Adin, 2005. 700 s. ISBN 80-89041-88-4.

[8] Čep, R.; Hatala, M.; Orlovský, I. Metody zkoušek obrobitelnosti materiálů. Automobil industry , 2009, č. 3.

[9] DAVIS, J. R. \& Associates. Aluminium and aluminium alloys. USA: ASM International, Handbook Committee, 1993. 5th edition, 784 s. ISBN 9780871704962.

[10] Sunil steel, Victoria Over Bridge Road 286, Opp. Britania Industries, Darukhana, Mumbai, India [online]. [cit. 19.3.2013]. Avaible on WWW: 〈http://www.sunilsteel.com/influence.htm>.

[11] TUMLÍK, Metal Cutting Technologies. Vliv jednotlivých prvků na vlastnosti ocelí [online]. [cit. 19.3.2011]. Avaible on WWW: <http://www.tumlikovo.cz/vliv-jednotlivych-prvku-na-vlastnosti-oceli/>.

[12] KLAPSIA, J., Vývoj v automatových ocelích, zvyšování obrobitelnosti bismutem, olovem v TŽ, a. s., Trinecké železárny, a.s., Trinec, Czech Republic, 2006.

[13] ACSteel a.s., Strojnická 374, 73701 Český Těšín, Zlepšení obrobitelnosti ocelí - akt. 4.11.2008 [online]. [cit. 19.3.2013]. Avaible on WWW: 〈http://www.acsteel.cz/down/obrobitelnost.oceli.pdf>.

[14] MAEKAWA, K.; OBIKAWA, T.; YAMANE, Y. Metal Machining: Theory and Applications. Butterworth-Heinemann; London : ARNOLD, 2000. 408 s. ISBN 0-340-69159-X.

[15] STRNAD, T. Obrobitelnost austenitické ocele. Plzeň, ZČU - FS, KTO, 2011.

[16] KŘíŽ, A., et al. Obrábění slitiny AlSiMg0,5Mn nástroji s progresivními tenkými vrstvami [online]. In: 5th international konference Aluminium, 2007. Staré Splavy. 21 s. Avaible on WWW: 〈http://www.ateam.zcu.cz/download/prispevek_Aluminium07.pdf>

[17] KOURIL, M., SPÁCILOVÁ, J. Nástroje pro obrábění hliníkových slitin s mikrolešteným povrchem. $M M$ Prumyslové spektrum č. 4., 2002. 61s. Avaible on WWW: <http://www.mmspektrum.com/clanek/nastroje-proobrabeni-hlinikovych-slitin-s-mikrolestenym-povrchem>

[18] Aluminium Taschenbuch, Aluminium-Verlag, Duseldorf, 1988.

[19] NOVAK, M. Surfaces with High Precision of Roughness after Grinding. In Manufacturing Technology, Vol. 
12., No. 12., pp. 66-70, ISSN 1213-2489.

[20] MADL, J., Surface Proprieties in Precise and Hard Machining. In Manufacturing Technology, Vol. 12., No. 13., pp. 158-166. ISSN 1213-2489.

[21] MADL, J., NAPRSTKOVA, N. Research into the causes cracking of aluminum alloys of Al - Cu during mechanical Machining. In Manufacturing Technology, Vol. 12., No. 12., pp. 47-51, ISSN 1213-2489. 